Provided for non-commercial research and education use. Not for reproduction, distribution or commercial use.

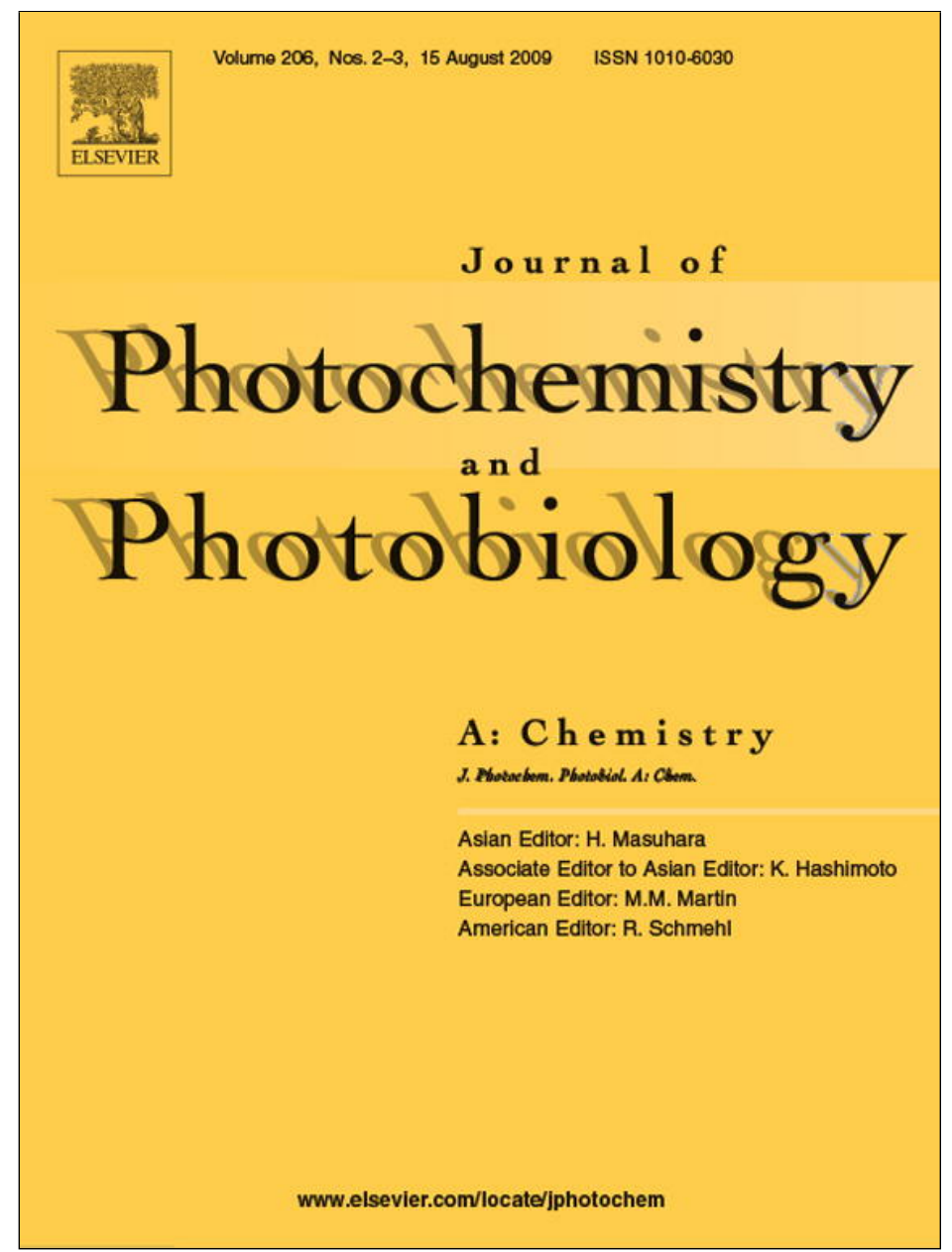

This article appeared in a journal published by Elsevier. The attached copy is furnished to the author for internal non-commercial research and education use, including for instruction at the authors institution and sharing with colleagues.

Other uses, including reproduction and distribution, or selling or licensing copies, or posting to personal, institutional or third party websites are prohibited.

In most cases authors are permitted to post their version of the article (e.g. in Word or Tex form) to their personal website or institutional repository. Authors requiring further information regarding Elsevier's archiving and manuscript policies are encouraged to visit:

http://www.elsevier.com/copyright 


\title{
Fluorescence properties of a potential antitumoral benzothieno[3,2-b]pyrrole in solution and lipid membranes
}

\author{
Elisabete M.S. Castanheira ${ }^{\mathrm{a}, *}$, Ana S. Abreu ${ }^{\mathrm{a}, \mathrm{b}}$, Maria-João R.P. Queiroz ${ }^{\mathrm{b}}$, Paula M.T. Ferreira ${ }^{\mathrm{b}}$, \\ Paulo J.G. Coutinho ${ }^{a}$, Nair Nazareth ${ }^{c}$, M. São-José Nascimento ${ }^{c}$ \\ a Centro de Física, Universidade do Minho, Campus de Gualtar, 4710-057 Braga, Portugal \\ ${ }^{\mathrm{b}}$ Centro de Química, Universidade do Minho, Campus de Gualtar, 4710-057 Braga, Portugal \\ c Laboratório de Microbiologia, Centro de Estudos de Química Medicinal, da Universidade do Porto (CEQUIMED-UP), Faculdade de Farmácia, \\ Rua Aníbal Cunha 164, 4050-047 Porto, Portugal
}

\section{A R T I C L E I N F O}

\section{Article history:}

Received 10 March 2009

Received in revised form 30 June 2009

Accepted 3 July 2009

\section{Keywords:}

Benzothienopyrrole

Antitumour properties

Fluorescence

Lipid membranes

\begin{abstract}
A B S T R A C T
Fluorescence properties of the antitumoral methyl 3-(benzo[b]thien-2-yl)-benzothieno[3,2-b]pyrrole-2carboxylate (BTP) were studied in solution and in lipid bilayers of dipalmitoyl phosphatidylcholine (DPPC), dioleoyl phosphatidylethanolamine (DOPE) and egg yolk phosphatidylcholine (Egg-PC). BTP presents good fluorescence quantum yields in all solvents studied $\left(0.20 \leq \Phi_{\mathrm{F}} \leq 0.32\right)$ and a bathochromic shift in polar solvents. The results indicate an ICT character of the excited state, with an estimated dipole moment of $\mu_{\mathrm{e}}=7.38 \mathrm{D}$.

Fluorescence (steady-state) anisotropy measurements of BTP incorporated in lipid membranes of DPPC, DOPE and Egg-PC indicate that this compound is deeply located in the lipid bilayer, feeling the difference between the rigid gel phase and fluid phases.

BTP inhibits the growth of three human tumour cell lines, MCF-7 (breast adenocarcinoma), SF-268 (glioma) and NCI-H460 (non-small cell lung cancer), being significantly more potent against the NCI-H460 tumour cells.
\end{abstract}

(C) 2009 Elsevier B.V. All rights reserved.

\section{Introduction}

Thienopyrroles are a very important class of biologically active compounds with antiviral [1] and anti-inflammatory properties [2]. Thienopyrroles have been widely used as SPLA2 inhibitors [3], MCP-1 antagonists [4] and glycogen phosphorylase inhibitors [5]. This type of compounds has also been described as gonadotrophin releasing hormone antagonists [6] and as bioisosteric analogues of tryptamine derivatives [7].

Due to their broad spectrum of biological activity, strong research efforts have been devoted to the synthesis of thienopyrroles and their derivatives [8]. The skeleton benzothieno[3,2$b$ ]pyrrole had already been synthesized by Iddon et al. [9] but, as far as our knowledge, no biological activity data have been reported on this type of compounds.

Abbreviations: DPPC, dipalmitoyl phosphatidylcholine; DOPE, dioleoyl phosphatidylethanolamine; Egg-PC, egg yolk phosphatidylcholine; PC, phosphatidylcholine; PE, phosphatidylethanolamine.

* Corresponding author. Tel.: +351253 604321; fax: +351253604061.

E-mail addresses: ecoutinho@fisica.uminho.pt, emsccoutinho@gmail.com (E.M.S. Castanheira).
Recently, some of us have synthesized several fluorescent (benzo[b]thienyl)benzothienopyrroles [10]. One of these compounds, a methyl 3-(benzo[b]thien-2-yl)benzothieno[3,2b]pyrrole-2-carboxylate (BTP) (Fig. 1) revealed promising antitumour properties, with a inhibitory activity of the in vitro growth of three human tumour cell lines, MCF-7 (breast adenocarcinoma), SF-268 (CNS cancer) and NCI-H460 (non-small cell lung cancer). The best anti-proliferative result was obtained for NCI$\mathrm{H} 460$ cell line, with a very low $\mathrm{GI}_{50}$ value (concentration needed for $50 \%$ of cell growth inhibition) around $3.9 \mu \mathrm{M}$, as reported here.

These promising results suggested us to perform fluorescence studies of BTP incorporated in lipid membranes. The photophysical properties of BTP in solution and in lipid bilayers of neutral phospholipid components of biological membranes, DPPC (dipalmitoyl phosphatidylcholine), DOPE (dioleoyl phosphatidylethanolamine) and Egg-PC (egg yolk phosphatidylcholine) were studied. Fluorescence (steady-state) anisotropy measurements were also performed to obtain further information about the behaviour of BTP in lipid membranes. These studies are important, keeping in mind the incorporation of this compound in liposomes for controlled drug delivery systems. In fact, liposomes have been widely used to deliver anticancer agents, in order to reduce the 
<smiles>CC(=O)c1[nH]c2c(sc3ccccc32)c1-c1cc2ccccc2s1</smiles>

Fig. 1. Structure of the benzothieno[3,2-b]pyrrole (BTP) studied.

toxic effects of the drugs when given alone or to increase the drug circulation time and effectiveness [11].

\section{Experimental}

\subsection{Materials and methods}

All the solutions were prepared using spectroscopic grade solvents and ultrapure water (Milli-Q grade). 1,2-Dipalmitoyl-snglycero-3-phosphocholine (DPPC), 1,2-dioleoyl-sn-glycero-3phosphoethanolamine (DOPE), and 1,2-diacyl-sn-glycero-3phosphocholine from egg yolk (Egg-PC) were obtained from SigmaAldrich (lipid structures are shown below). with double monochromators in both excitation and emission, Glan-Thompson polarizers and a temperature controlled cuvette holder. Fluorescence spectra were corrected for the instrumental response of the system.

For fluorescence quantum yield determination, the solutions were previously bubbled for $20 \mathrm{~min}$ with ultrapure nitrogen. The fluorescence quantum yields $\left(\Phi_{\mathrm{s}}\right)$ were determined using the standard method (Eq. (1)) [13,14]. 9,10-Diphenylanthracene in ethanol was used as reference, $\Phi_{r}=0.95[15]$ :

$\Phi_{\mathrm{s}}=\left[\frac{A_{\mathrm{r}} F_{\mathrm{s}} n_{\mathrm{s}}^{2}}{A_{\mathrm{s}} F_{\mathrm{r}} n_{\mathrm{r}}^{2}}\right] \Phi_{\mathrm{r}}$

where $A$ is the absorbance at the excitation wavelength, $F$ the integrated emission area and $n$ the refraction index of the solvents used. Subscripts refer to the reference ( $r$ ) or sample (s) compound. The absorbance value at excitation wavelength was always less than 0.1 , in order to avoid inner filter effects.

Solvatochromic shifts were described by the Lippert-Mataga equation (2), which relates the energy difference between absorption and emission maxima to the orientation polarizability [16,17]:

$\bar{v}_{\mathrm{abs}}-\bar{v}_{\mathrm{fl}}=\frac{1}{4 \pi \varepsilon_{0}} \frac{2 \Delta \mu^{2}}{h c R^{3}} \Delta f+$ const

where $\bar{v}_{\mathrm{abs}}$ is the wave number of maximum absorption, $\bar{v}_{\mathrm{fl}}$ is the wave number of maximum emission, $\Delta \mu=\mu_{\mathrm{e}}-\mu_{\mathrm{g}}$ is the<smiles>CCCCCCCCCCCCCCCCCCCCCCCC(=O)OC[C@H](COP(=O)([O-])OCC[N+](C)(C)C)OC(=O)CCCCC</smiles><smiles></smiles><smiles>[R]C(=O)OC[C@H]([2H])OC[C@H]([R])OP(=O)([O-])OCC[N+](C)(C)C</smiles>

DOPE

\section{Egg-PC}

For DOPE and Egg-PC membranes preparation, defined volumes of stock solutions of lipid $(26.9 \mathrm{mM}$ for DOPE and $34.5 \mathrm{mM}$ for Egg-PC) and BTP $(0.2 \mathrm{mM})$ in ethanol were injected together, under vigorous stirring, to an aqueous buffer solution ( $10 \mathrm{mM}$ Tris, $1 \mathrm{mM}$ EDTA, pH 7.4), at room temperature. A similar procedure was adopted for DPPC vesicles, but the injection of the required amounts of stock solutions of lipid ( $50 \mathrm{mM})$ and BTP in ethanol was done at $60^{\circ} \mathrm{C}$, well above the melting transition temperature of DPPC ( $c a$. $41^{\circ} \mathrm{C}$ ) [12]. In all cases, the final lipid concentration was $1 \mathrm{mM}$, with a BTP/lipid molar ratio of 1:500.

\subsection{Spectroscopic measurements}

Absorption spectra were recorded in a Shimadzu UV-3101PC UV-Vis-NIR spectrophotometer. Fluorescence measurements were performed using a Fluorolog 3 spectrofluorimeter, equipped difference in the dipole moment of solute molecule between excited $\left(\mu_{\mathrm{e}}\right)$ and ground $\left(\mu_{\mathrm{g}}\right)$ states, $R$ is the cavity radius (considering the fluorophore a point dipole at the center of a spherical cavity immersed in the homogeneous solvent), and $\Delta f$ is the orientation polarizability given by (Eq. (3)):

$\Delta f=\frac{\varepsilon-1}{2 \varepsilon+1}-\frac{n^{2}-1}{2 n^{2}+1}$

where $\varepsilon$ is the static dielectric constant and $n$ the refractive index of the solvent.

The steady-state fluorescence anisotropy, $r$, is calculated by:

$r=\frac{I_{\mathrm{VV}}-G I_{\mathrm{VH}}}{I_{\mathrm{VV}}+2 G I_{\mathrm{VH}}}$

where $I_{\mathrm{VV}}$ and $I_{\mathrm{VH}}$ are the intensities of the emission spectra obtained with vertical and horizontal polarization, respectively 
(for vertically polarized excitation light), and $G=I_{\mathrm{HV}} / I_{\mathrm{HH}}$ is the instrument correction factor, where $I_{\mathrm{HV}}$ and $I_{\mathrm{HH}}$ are the emission intensities obtained with vertical and horizontal polarization (for horizontally polarized excitation light).

\subsection{Biological activity}

\subsubsection{Materials}

Fetal bovine serum (FBS) and L-glutamine were obtained from Gibco Invitrogen Co. (Scotland, UK). RPMI-1640 medium was from Cambrex (New Jersey, USA). Dimethylsulfoxide (DMSO), doxorubicin, penicillin, streptomycin and sulforhodamine B (SRB) were from Sigma Chemical Co. (Saint Louis, USA).

Stock solution of BTP was prepared in DMSO and kept at $-20^{\circ} \mathrm{C}$. Appropriate dilutions of the compound were freshly prepared just prior to the assays. Final concentrations of DMSO did not interfere with the cell lines growth.

\subsubsection{Cell cultures}

Three human tumour cell lines, MCF-7 (breast adenocarcinoma), SF-268 (glioma) and NCI-H460 (non-small cell lung cancer) were used. MCF-7 was obtained from the European Collection of Cell Cultures (ECACC, Salisbury, UK). SF-268 and NCI-H460 were kindly provided by the National Cancer Institute $(\mathrm{NCI}$, Bethesda, USA). Cells were grown as monolayer and routinely maintained in RPMI-1640 medium supplemented with $5 \%$ heat inactivated FBS, $2 \mathrm{mM}$ glutamine and antibiotics (penicillin $100 \mathrm{U} / \mathrm{ml}$ and streptomycin $100 \mu \mathrm{g} / \mathrm{ml}$ ), at $37^{\circ} \mathrm{C}$ in a humidified atmosphere containing $5 \% \mathrm{CO}_{2}$. Exponentially growing cells were obtained by plating $1.5 \times 10^{5}$ cells $/ \mathrm{ml}$ for MCF-7 and SF-268 and $0.75 \times 10^{5}$ cells $/ \mathrm{ml}$ for $\mathrm{NCI}-\mathrm{H} 460$, followed by $24 \mathrm{~h}$ incubation. The effect of the vehicle solvent (DMSO) on the growth of these cell lines was evaluated in all the experiments by exposing untreated control cells to the maximum concentration $(0.5 \%)$ of DMSO used in each assay.

\subsubsection{Tumour cells growth assay}

The effect of BTP on the in vitro growth of human tumour cell lines was evaluated according to the procedure adopted by the National Cancer Institute (NCI, USA) in the "In vitro Anticancer Drug Discovery Screen" that uses the protein-binding dye sulforhodamine B to assess cell growth [18-19]. Briefly, exponentially cells growing in 96 -well plates were exposed for $48 \mathrm{~h}$ to five serial concentrations of BTP, starting from a maximum concentration of $150 \mu \mathrm{M}$. Following this exposure period, adherent cells were fixed, washed and stained. The bound stain was solubilized and the absorbance was measured at $492 \mathrm{~nm}$ in a plate reader (BioTek Instruments Inc., Powerwave XS, Winooski, USA). A dose-response curve was obtained and the growth inhibition of $50 \%\left(\mathrm{GI}_{50}\right)$, corresponding to the concentration of BTP that inhibited $50 \%$ of the net cell growth was calculated as described elsewhere [19]. Doxorubicin used as a positive control was tested in the same manner.

\section{Results and discussion}

\subsection{Antitumoral properties of $\boldsymbol{B T P}$}

The effect of the benzothienopyrrole BTP on the in vitro growth of three human tumour cell lines, MCF-7 (breast adenocarcinoma), SF-268 (CNS cancer) and NCI-H460 (non-small cell lung cancer), was evaluated after a continuous exposure of $48 \mathrm{~h}$. Results given in concentrations that were able to cause $50 \%$ of cell growth inhibition $\left(\mathrm{GI}_{50}\right)$ are summarized in Table 1.

It can be observed in Table 1 that BTP inhibited the growth of all the three human tumour cell lines, but it was significantly much more potent against the lung cancer $\mathrm{NCl}-\mathrm{H} 460$ cell line, presenting a very low $\mathrm{GI}_{50}$ value $(3.9 \pm 0.3 \mu \mathrm{M})$. BTP presents $\mathrm{GI}_{50}$ values

\section{Table 1}

Values of BTP concentration needed for $50 \%$ of cell growth inhibition $\left(\mathrm{GI}_{50}\right)$ for three human tumour cell lines.

\begin{tabular}{lc}
\hline Cell line & $\mathrm{GI}_{50}(\mu \mathrm{M})$ \\
\hline MCF-7 & $19.1 \pm 11.5$ \\
SF-268 & $38.7 \pm 8.9$ \\
NCI-H460 & $3.9 \pm 0.3$ \\
\hline
\end{tabular}

Results represent means \pm SEM of $3-4$ independent experiments performed in duplicate. Doxorubicin was used as positive control, $\mathrm{GI}_{50}$ : MCF-7 $=42.8 \pm 8.2 \mathrm{nM} ; \quad$ SF-268 $=94.0 \pm 7.0 \mathrm{nM}$ and $\mathrm{NCl}-\mathrm{H} 460=94.0 \pm 8.7 \mathrm{nM}$.

lower or of the same magnitude of other compounds recently tested in the same tumour cell lines and also considered as potential antitumorals [20,21]. The BTP different cell line response may reflect a possible tumour type-specific sensitivity of this compound which is very important for its potential use in the treatment of this type of tumour.

Doxorubicin, used as positive control, presents a very high cytotoxicity because the planar aromatic part efficiently intercalates into DNA base pairs, while the six-membered daunosamine sugar binds to the minor groove, interacting with flanking base pairs adjacent to the intercalation site [22]. Nevertheless, doxorubicin presents also a high toxicity for the human body and the search for other antitumour compounds even less active but also less toxic is still an active domain of interest.

\subsection{Photophysical properties of $\boldsymbol{B T P}$ in solution}

The absorption and fluorescence properties of BTP were first studied in several solvents. The maximum absorption $\left(\lambda_{\mathrm{abs}}\right)$ and emission $\left(\lambda_{\mathrm{em}}\right)$ wavelengths, molar extinction coefficients and fluorescence quantum yields are presented in Table 2 .

In pyrrole and its derivatives, the heteronitrogen is singly bonded to carbon atoms in the heterocycle. The transitions involving the non-bonding electrons have properties similar to those of $\pi \rightarrow \pi^{*}$ transitions, as the non-bonding orbital is perpendicular to the plane of the ring, which allows it to overlap the $\pi$ orbitals on the adjacent carbon atoms [23]. BTP compound also presents a carboxylate group and it is known that many carbonyl compounds exhibit low fluorescence quantum yields due to the low-lying $n \rightarrow \pi^{*}$ state. In BTP, it is possible that the electronic transitions $\pi \rightarrow \pi^{*}$ and $n \rightarrow \pi^{*}$ can be nearby in energy, resulting in state-mixing [24]. A predominance of $\pi \rightarrow \pi^{*}$ character could explain the high $\varepsilon$ values $\left(\varepsilon>10^{4} \mathrm{M}^{-1} \mathrm{~cm}^{-1}\right)$ and the very reasonable fluorescence quantum yields (Table 2 ).

The normalized fluorescence spectra of BTP are shown in Fig. 2. Examples of absorption spectra are shown as inset.

A red shift can be observed from cyclohexane to more polar solvents, especially in fluorescence spectra. A complete loss of vibrational structure is also observed for the emission in polar solvents (Fig. 2), which is usually related to an intramolecular charge transfer (ICT) mechanism and/or to specific solvent effects [16]. This behaviour was already observed by us for tetracyclic benzothiophene derivatives, a thieno- $\delta$-carboline and a methoxylated benzothieno[2,3-c]quinolone, synthesized by our group [25,26].

The Lippert-Mataga plot (Eq. (2)) for BTP, shown in Fig. 3, is reasonably linear in non-protic solvents, alcohols and chloroform exhibiting large positive deviations.

This behaviour in alcohols and chloroform can be attributed to specific solute-solvent interactions by hydrogen bonds. The formation of hydrogen bonds between chloroform and proton acceptors is known since a long time [28]. In fact, BTP has the capability of hydrogen bonding formation through the ester group 
Table 2

Maximum absorption $\left(\lambda_{\mathrm{abs}}\right)$ and emission wavelengths $\left(\lambda_{\mathrm{em}}\right)$, molar extinction coefficients $(\varepsilon)$ and fluorescence quantum yields $\left(\Phi_{\mathrm{F}}\right)$ for BTP in several solvents.

\begin{tabular}{|c|c|c|c|}
\hline Solvent & $\lambda_{\mathrm{abs}}(\mathrm{nm})\left(\varepsilon\left(\mathrm{M}^{-1} \mathrm{~cm}^{-1}\right)\right)$ & $\lambda_{\text {em }}(\mathrm{nm})$ & $\Phi_{\mathrm{F}}^{\mathrm{a}}$ \\
\hline Cyclohexane & $\begin{array}{l}320 \operatorname{sh}\left(2.33 \times 10^{4}\right) \\
294\left(3.30 \times 10^{4}\right) \\
264\left(3.10 \times 10^{4}\right) \\
230\left(3.26 \times 10^{4}\right)\end{array}$ & 396 & 0.31 \\
\hline Dioxane & $\begin{array}{l}321 \mathrm{sh}\left(2.59 \times 10^{4}\right) \\
297\left(3.81 \times 10^{4}\right) \\
263\left(3.36 \times 10^{4}\right) \\
228\left(4.15 \times 10^{4}\right)\end{array}$ & 398 & 0.29 \\
\hline Diethyl ether & $\begin{array}{l}322 \operatorname{sh}\left(1.67 \times 10^{4}\right) \\
294\left(2.46 \times 10^{4}\right) \\
263\left(2.03 \times 10^{4}\right) \\
231\left(1.92 \times 10^{4}\right)\end{array}$ & 396 & 0.20 \\
\hline Ethyl acetate & $\begin{array}{l}324 \operatorname{sh}\left(1.67 \times 10^{4}\right) \\
295\left(2.57 \times 10^{4}\right)^{b}\end{array}$ & 399 & 0.32 \\
\hline Dichloromethane & $\begin{array}{l}326 \operatorname{sh}\left(2.62 \times 10^{4}\right) \\
296\left(3.79 \times 10^{4}\right) \\
265\left(3.36 \times 10^{4}\right) \\
226\left(4.35 \times 10^{4}\right)\end{array}$ & 401 & 0.27 \\
\hline Chloroform & $\begin{array}{l}328 \operatorname{sh}\left(1.70 \times 10^{4}\right) \\
297\left(2.30 \times 10^{4}\right) \\
266\left(2.10 \times 10^{4}\right)^{b}\end{array}$ & 406 & 0.30 \\
\hline Acetonitrile & $\begin{array}{l}326 \operatorname{sh}\left(2.24 \times 10^{4}\right) \\
294\left(3.50 \times 10^{4}\right) \\
262\left(2.94 \times 10^{4}\right) \\
228\left(3.54 \times 10^{4}\right)\end{array}$ & 399 & 0.23 \\
\hline $\mathrm{N}, \mathrm{N}$-Dimethylformamide & $\begin{array}{l}328 \operatorname{sh}\left(3.09 \times 10^{4}\right) \\
297\left(4.86 \times 10^{4}\right)^{\mathrm{b}}\end{array}$ & 402 & 0.29 \\
\hline Dimethylsulfoxide & $\begin{array}{l}331 \mathrm{sh}\left(3.20 \times 10^{4}\right) \\
299\left(5.04 \times 10^{4}\right)^{\mathrm{b}}\end{array}$ & 406 & 0.29 \\
\hline Ethanol & $\begin{array}{l}327 \mathrm{sh}\left(2.73 \times 10^{4}\right) \\
295\left(4.24 \times 10^{4}\right) \\
264\left(3.50 \times 10^{4}\right) \\
229\left(4.03 \times 10^{4}\right)\end{array}$ & 407 & 0.20 \\
\hline Methanol & $\begin{array}{l}328 \mathrm{sh}\left(2.91 \times 10^{4}\right) \\
294\left(4.47 \times 10^{4}\right) \\
263\left(3.76 \times 10^{4}\right) \\
228\left(4.36 \times 10^{4}\right)\end{array}$ & 411 & 0.20 \\
\hline
\end{tabular}

sh, shoulder

a Relative to 9,10-diphenylanthracene in ethanol ( $\Phi_{\mathrm{r}}=0.95$ [15]). Error about $10 \%$.

b Solvents cut-off: chloroform, $250 \mathrm{~nm}$; ethyl acetate, $265 \mathrm{~nm}$; dimethylsulfoxide, $270 \mathrm{~nm} ; \mathrm{N}, \mathrm{N}$-dimethylformamide, $275 \mathrm{~nm}$.

(acceptor), the two S atoms (acceptors) and also the pyrrolic $\mathrm{NH}$ group (donor).

From ab initio molecular quantum chemistry calculations, the cavity radius $(R)$ and ground state dipole moment $\left(\mu_{\mathrm{g}}\right)$ were determined, through an optimized structure provided by GAMESS software [29], using a RHF/3-21G(d) basis set [30] (Fig. 4). The BTP optimized geometry shows that the benzo[b]thienyl substituent of the molecule is almost perpendicular to the benzothienopyrrole system. A cavity radius of $7.9 \AA$ and a ground state dipole moment of 1.24 $\mathrm{D}$ were obtained, allowing the estimation of an excited-state dipole moment of $\mu_{\mathrm{e}}=7.38 \mathrm{D}$ from the Lippert-Mataga plot. This $\mu_{\mathrm{e}}$ value points to the presence of an intramolecular charge transfer (ICT) mechanism occurring in the planar benzothienopyrrole moiety, although not very pronounced. Twisted intramolecular charge transfer states (TICT) usually exhibit significantly higher excitedstate dipole moments ( $\geq 20 \mathrm{D}$ ) [31] than the value obtained for BTP.

Fig. 5 reports the representation of BTP HOMO and LUMO molecular orbitals. It can be observed that both molecular orbitals are localized on the benzothienopyrrole moiety and also on the methylester group. The HOMO-LUMO transition exhibits a charge transfer from the $S$ atom of the benzothienopyrrole system to both

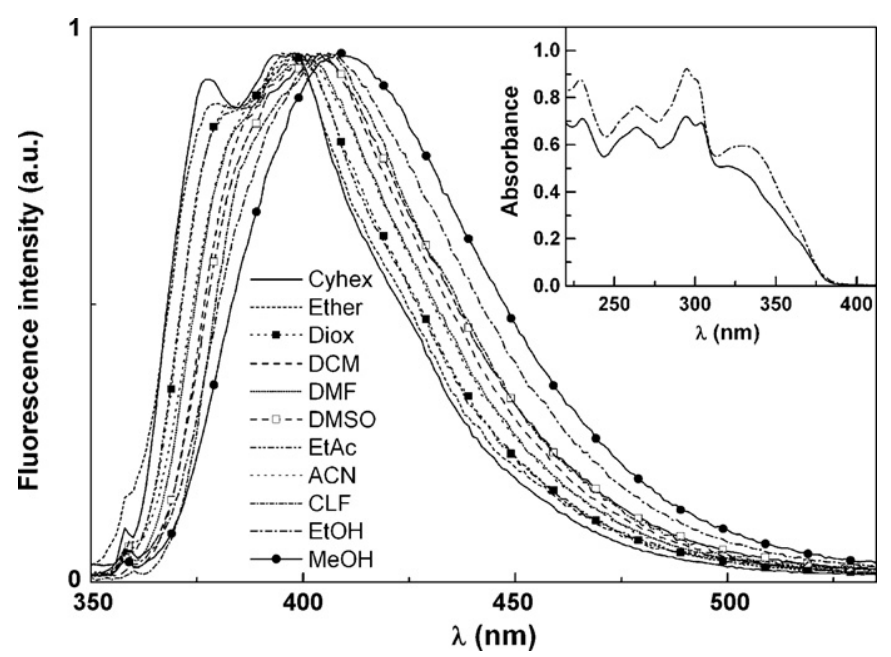

Fig. 2. Normalized fluorescence spectra (at peak of maximum emission) of $3 \times 10^{-6} \mathrm{M}$ solutions of BTP in several solvents $\left(\lambda_{\text {exc }}=325 \mathrm{~nm}\right.$ ) (Cyhex, cyclohexane; Ether, diethyl ether; Diox, dioxane; DCM, dichloromethane; DMF, $\mathrm{N}, \mathrm{N}$-dimethylformamide; DMSO, dimethylsulfoxide; EtAc, ethyl acetate; ACN, acetonitrile; CLF, chloroform; EtOH, ethanol; $\mathrm{MeOH}$, methanol). Inset: absorption spectra of $2 \times 10^{-5} \mathrm{M}$ solutions of BTP in cyclohexane and ethanol, as examples (cell path $=1.0 \mathrm{~cm}$ ).

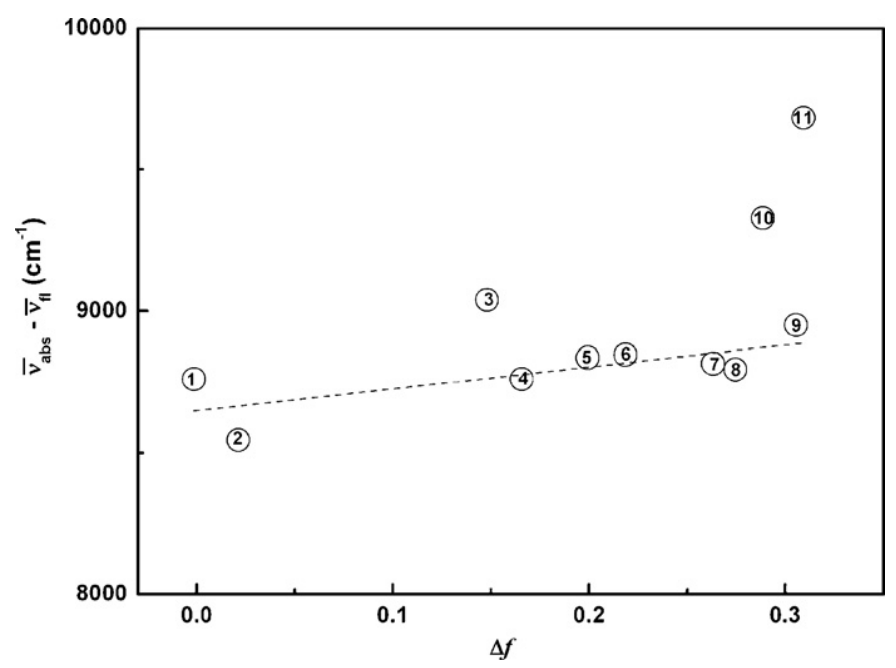

Fig. 3. Lippert-Mataga plot for BTP: (1) cyclohexane; (2) dioxane; (3) chloroform; (4) diethyl ether; (5) ethyl acetate; (6) dichloromethane; (7) dimethylsulfoxide; (8) $\mathrm{N}, \mathrm{N}$-dimethylformamide; (9) acetonitrile; (10) ethanol; (11) methanol (values of $\varepsilon$ and $n$ were obtained from Ref. [27]).

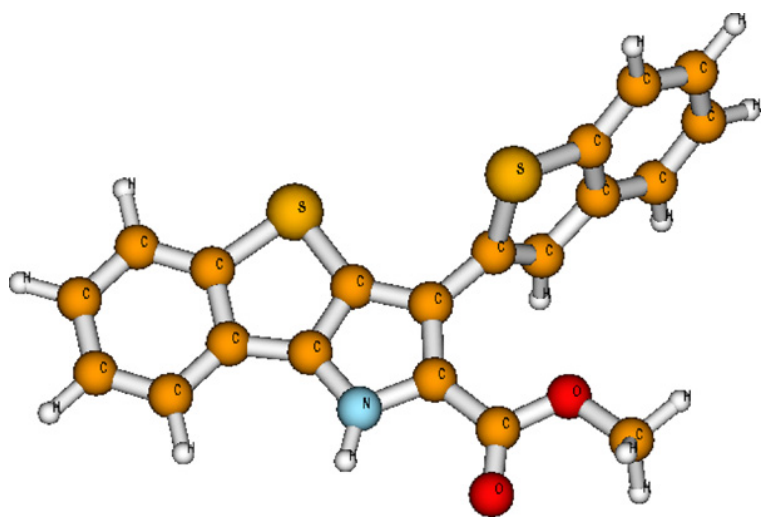

Fig. 4. Optimized structure of BTP (obtained by GAMESS software). 


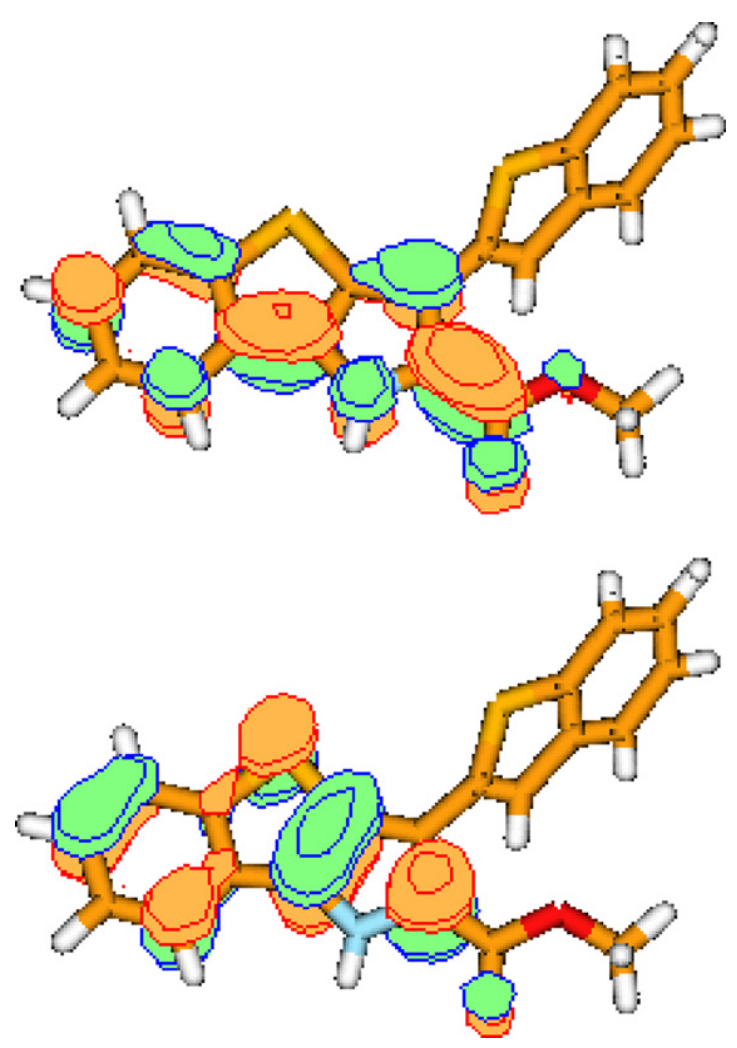

Fig. 5. Representation of HOMO (lower) and LUMO (upper) molecular orbitals of BTP.

the nitrogen and the OMe oxygen, confirming the ICT character of the excited state.

The benzo[b]thienyl substituent does not contribute to increase non-radiative deactivation pathways in BTP. This justifies the reasonable fluorescence quantum yields obtained (between $20 \%$ and $32 \%$, Table 2 ), despite the presence of two $\mathrm{S}$ atoms in the molecule, which usually lead to the increase of singlet-triplet intersystem crossing by enhancement of spin-orbit coupling interaction [24]. The contribution of $\mathrm{S}$ atoms to decrease the fluorescence quantum yield is less important for BTP than for other analogues like benzothienoindoles with a dibenzothienyl substituent already synthesized and studied by us [32].

\subsection{Interaction of $\boldsymbol{B T P}$ with lipid membranes}

Due to its promising antitumoral activity, photophysical studies of BTP incorporated in lipid bilayers were also performed. These studies are relevant to evaluate the interaction of the compound with lipid membranes. Assessment of the localization of BTP in lipid vesicles is also important, pointing to drug delivery applications using liposomes.

Different types of phospholipid molecules, DPPC, Egg-PC and DOPE, were used for vesicle preparation. At room temperature, DPPC (16:0 PC) is in the ordered gel phase, where the hydrocarbon chains are fully extended and closely packed. Above the melting transition temperature, $T_{\mathrm{m}}=41^{\circ} \mathrm{C}$ [12], DPPC attains the disordered liquid-crystalline phase. DOPE (18:1 PE) exhibits a very low melting transition temperature $\left(T_{\mathrm{m}}=-16^{\circ} \mathrm{C}\right.$ [33] $)$ and presents a lamellar bilayer to inverse hexagonal $\left(\mathrm{L}_{\alpha}-\mathrm{H}_{\mathrm{II}}\right)$ phase transition at $3.3^{\circ} \mathrm{C}[34]$. Egg-PC is a natural phospholipid mixture, where molecules have the same polar head group (phosphatidylcholine) and different hydrocarbon chains, differing in length and degree of unsaturation. Main components are 16:0 PC, 18:0 PC and 18:1 PC [35]. Therefore, at room temperature, Egg-PC is in the fluid liquid-crystalline phase.

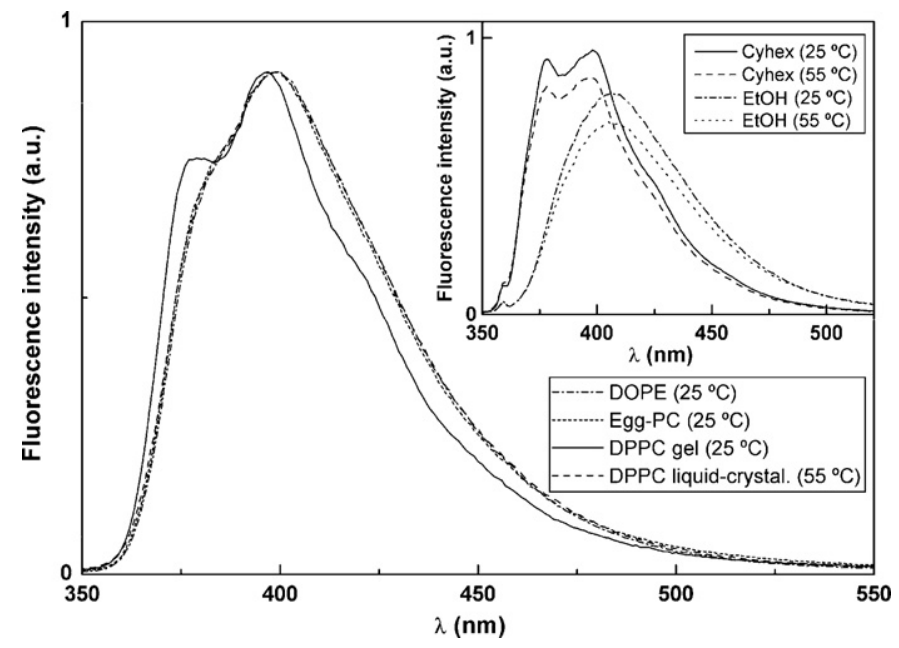

Fig. 6. Normalized fluorescence spectra of BTP in lipid membranes of DOPE, Egg-PC and DPPC $\left(\lambda_{\text {exc }}=325 \mathrm{~nm}\right)$. Inset: fluorescence spectra of BTP in cyclohexane (Cyhex) and ethanol (EtOH), at 25 and $55^{\circ} \mathrm{C}$.

In DPPC vesicles at gel phase $\left(25^{\circ} \mathrm{C}\right)$, the emission spectrum of BTP is very similar in shape and position to those in cyclohexane and diethyl ether (Fig. 6 and Table 3), indicating that BTP is located deeply inside the lipid bilayer. When DPPC is in the liquid-crystalline phase (at $55^{\circ} \mathrm{C}$ ), a structureless and red-shifted emission is observed, similar to the spectra obtained in dioxane and ethyl acetate. A decrease in emission intensity of about $25 \%$ is also detected.

In homogeneous solution, the effect of increasing temperature in the fluorescence of BTP is a $10 \%$ intensity reduction and a very small blue shift (ca. $1 \mathrm{~nm}$ ). The inset of Fig. 6 shows BTP emission spectra in cyclohexane and ethanol at 25 and $55^{\circ} \mathrm{C}$, where it can be seen that the spectral shape is roughly the same at both temperatures.

The red shift and loss of vibrational structure of BTP emission in lipid membranes at fluid phases (DOPE and Egg-PC at $25^{\circ} \mathrm{C}$ and DPPC at $55^{\circ} \mathrm{C}$ ) point to a higher penetration of water molecules in the vesicle bilayer, as lipid hydrocarbon chains are randomly oriented and fluid. However, it is also possible that in fluid phases BTP locates in a more polar environment, near the ester groups of the phospholipid molecules.

Fluorescence anisotropy measurements can give further information about BTP behaviour in lipid membranes. Steady-state anisotropy relates to both the excited-state lifetime and the rotational correlation time of the fluorophore [23]:

$\frac{1}{r}=\frac{1}{r_{0}}\left(1+\frac{\tau}{\tau_{\mathrm{c}}}\right)$

where $r_{0}$ is the fundamental anisotropy, $\tau$ is the excited-state lifetime and $\tau_{\mathrm{c}}$ is the rotational correlation time.

The fluorescence steady-state anisotropies and fluorescence quantum yields of BTP in lipid bilayers are shown in Table 3.

Table 3

Steady-state fluorescence anisotropy $(r)$ values, fluorescence quantum yields and maximum emission wavelengths ( $\lambda_{\text {em }}$ ) of BTP in lipid membranes. Values in ethylene glycol at room temperature are also shown for comparison.

\begin{tabular}{llll}
\hline & $\lambda_{\text {em }}(\mathrm{nm})$ & $\Phi_{\mathrm{F}}{ }^{\mathrm{a}}$ & $r$ \\
\hline Egg-PC $\left(25^{\circ} \mathrm{C}\right)$ & 400 & 0.24 & 0.046 \\
DOPE $\left(25^{\circ} \mathrm{C}\right)$ & 399 & 0.27 & 0.023 \\
$\operatorname{DPPC}\left(25^{\circ} \mathrm{C}\right)$ & 397 & 0.26 & 0.058 \\
DPPC $\left(55^{\circ} \mathrm{C}\right)$ & 399 & 0.11 & 0.036 \\
Ethylene glycol $\left(25^{\circ} \mathrm{C}\right)$ & 415 & 0.29 & 0.036 \\
\hline
\end{tabular}

\footnotetext{
a Relative to 9,10-diphenylanthracene in ethanol ( $\Phi_{\mathrm{r}}=0.95$ [15]). Error about $10 \%$.
} 


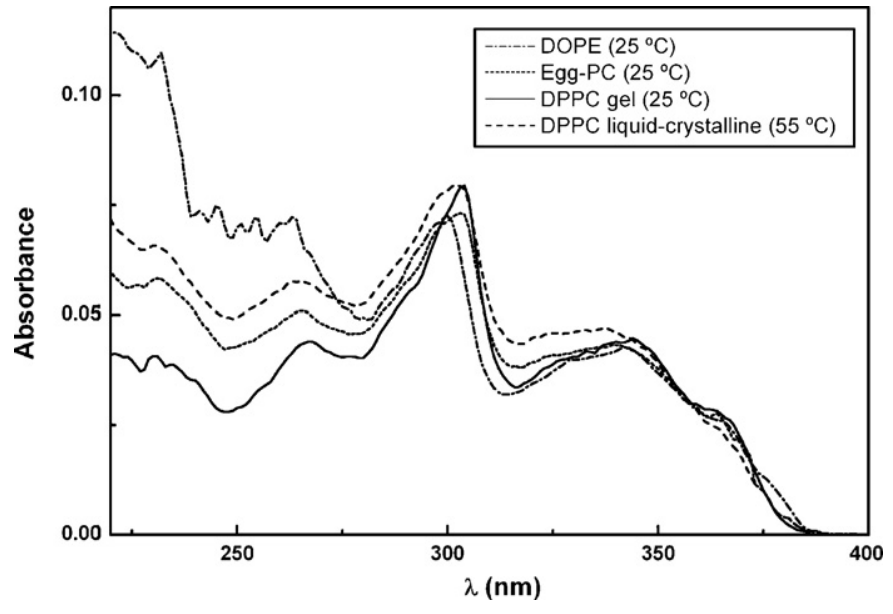

Fig. 7. Absorption spectra of BTP $\left(2 \times 10^{-6} \mathrm{M}\right)$ in lipid membranes of DOPE, Egg-PC and DPPC at both gel $\left(25^{\circ} \mathrm{C}\right)$ and liquid-crystalline phases $\left(55^{\circ} \mathrm{C}\right)$.

Anisotropy and quantum yield values in ethylene glycol at room temperature were also determined for comparison.

Fluorescence quantum yields are roughly similar in all lipid bilayers and in ethylene glycol at $25^{\circ} \mathrm{C}$, with a small decrease in EggPC. The Strickler-Berg equation [36] relates the radiative lifetime with the absorption intensity (Eq. (6)):

$\frac{1}{\tau_{\mathrm{r}}}=2.88 \times 10^{-9} n^{2} \frac{\int F_{\bar{\nu}}\left(\bar{\nu}_{\mathrm{F}}\right) \mathrm{d} \bar{\nu}_{\mathrm{F}}}{\int \bar{v}_{\mathrm{F}}^{-3} F_{\bar{\nu}}\left(\bar{\nu}_{\mathrm{F}}\right) \mathrm{d} \bar{\nu}_{\mathrm{F}}} \int \frac{\varepsilon\left(\bar{\nu}_{\mathrm{A}}\right) \mathrm{d} \bar{\nu}_{\mathrm{A}}}{\bar{\nu}_{\mathrm{A}}}$

where $\tau_{\mathrm{r}}$ is the radiative lifetime, $n$ is the refraction index, $\varepsilon$ is the molar extinction coefficient, and $F_{\bar{v}}\left(\bar{v}_{\mathrm{F}}\right)$ is the fluorescence intensity per unit wave number, which is related to the fluorescence quantum yield [23] (Eq. (7)):

$\int_{\infty}^{0} F_{\bar{\nu}}\left(\bar{v}_{\mathrm{F}}\right) \mathrm{d} \bar{v}_{\mathrm{F}}=\Phi_{\mathrm{F}}$

Absorption spectra of BTP in the various lipid membranes at $25^{\circ} \mathrm{C}$ (Fig. 7) are similar in the lowest energy absorption band. The Stickler-Berg relation (Eq. (6)) predicts an approximately constant value for the radiative lifetime in the three lipid membranes, considering the very small variations of the measured fluorescence quantum yields (Table 3 ).

The relation between the fluorescence quantum yield and the excited-state lifetime:

$\Phi_{\mathrm{F}}=k_{\mathrm{r}} \tau$

where $k_{\mathrm{r}}=1 / \tau_{\mathrm{r}}$ is the rate constant for radiative deactivation with fluorescence emission, allows the conclusion that the excited-state lifetimes are approximately constant for the studied lipid systems at $25^{\circ} \mathrm{C}$. Therefore, variations in fluorescence anisotropy values at this temperature can be directly related to changes in the rotational correlation time of the fluorophore and, thus, to changes in the microviscosity of the surrounding medium of the fluorescent molecule. It can be observed that $r$ values in DPPC at gel phase $\left(25^{\circ} \mathrm{C}\right)$ and in Egg-PC are higher than the one obtained in ethylene glycol, indicating that BTP is deeply located in the lipid bilayer. The steady-state anisotropy in Egg-PC is higher than expected, comparing all anisotropy values in lipid bilayers at fluid phases (Egg-PC, DOPE and DPPC at $55^{\circ} \mathrm{C}$ ). A similar behaviour in Egg-PC was already observed for indole-2-carboxylate derivatives, prepared by us, substituted in the 3-position with either a dibenzothiophene or a dibenzofuran [37].

The phospholipid DOPE, at room temperature, adopts the inverse hexagonal phase, where the lipid molecules can adopt inverse curvature at the interface, allowing the chains to expand and at the same time reduce the head group area at the interface [38]. The very low anisotropy value observed in DOPE (Table 3) reflects the different geometry of self-organized DOPE aggregates, through the mentioned chain expansion. The emission spectrum (Fig. 6) shows that BTP feels a similar environment in DOPE to that in Egg-PC and DPPC at the liquid-crystalline phase.

In DPPC at $55^{\circ} \mathrm{C}$, a significant fluorescence quenching (Table 3 ) is observed due to the increase of the non-radiative deactivation pathways at higher temperatures. According to Eq. (5), an increase of the steady-state anisotropy is predicted from a decrease of the excitedstate lifetime. BTP exhibits a significant decrease in anisotropy in DPPC at $55^{\circ} \mathrm{C}$ (Table 3), showing that this molecule detects the phospholipid gel to liquid-crystalline phase transition and the associated decrease of microviscosity. The anisotropy value in the DPPC fluid phase is similar to the one in ethylene glycol at $25^{\circ} \mathrm{C}$, as observed in heteroaryl and heteroannulated indoles [37]. The results obtained in DPPC vesicles clearly indicate that BTP is located deeply in the lipid bilayer and that the red shift in emission at $55^{\circ} \mathrm{C}$ may be due to the higher water penetration and not to a different localization of BTP in fluid phases.

Liposomes have been widely employed to deliver anticancer agents. Considering the BTP antitumoral activity and its preferential location near the phospholipid tails of lipid membranes, these studies are also important to drug delivery assays using liposomes.

\section{Conclusions}

The methyl 3-(benzo[b]thien-2-yl)benzothieno[3,2-b]pyrrole2-carboxylate (BTP) interferes with the growth of different human tumour cell lines, exhibiting a stronger effect against the NCI-H460 lung cancer cell line.

This compound shows a solvent sensitive fluorescence emission and very reasonable fluorescence quantum yields (20-32\%) in both polar and non-polar solvents. The estimated excited-state dipole moment $(7.38 \mathrm{D})$ points to an ICT character of the excited state, confirmed by molecular quantum chemistry calculations.

Studies of incorporation in lipid bilayers revealed that BTP preferential location is near the hydrophobic lipid tails. Overall, these results point to a promising use of BTP as an antitumoral drug with the possibility of being transported in the hydrophobic region of liposomes.

\section{Acknowledgements}

We acknowledge the Foundation for the Science and Technology (FCT) - Portugal and FEDER (European Communitarian Fund) for financial support to Centro de Física and Centro de Química of Minho University, through the project PTDC/QUI/81238/2006. Computational facilities supported by FCT and University of Minho under project SeARCH (ref. REEQ/443/ EEI/2005) are also acknowledged. A.S.A. acknowledges FCT for a post-doc. Grant SFRH/BPD/24548/2005.

\section{References}

[1] (a) B. Attenni, J.I.M. Hernando, S. Malancona, F. Narjes, J. M. Ontoria Ontoria, M. Rowley, Thienopyrroles as Antiviral Agents, Istituto di Ricerche di Biologia Molecolare P Angeletti S.p.A., Italy, WO/2005/023819, 2005.;

(b) S. Colarusso, J. Habermann, F. Narjes, S. Ponzi, M.R. Rico Ferreira, Thienopyrroles as Antiviral Agents, Istituto di Ricerche di Biologia Molecolare P Angeletti S.p.A., Italy, WO/2006/119975, 2006.

[2] B. Pelcman, K. Olofsson, P. Arsenjans, V. Ozola, E. Suna, I. Kalvins, Thienopyrroles Useful in the Treatment of Inflammation, Biolipox AB, Solna, SE, WO/2006/077412, 2006.

[3] D.W. Beight, J.M. Morin, Jr., J.S. Sawyer, E.C.R. Smith, Substituted Pyrrole Compounds and Their Use as sPLA2 Inhibitors, Eli Lilly \& Co., Indianapolis, US, WO/2002/012249, 2002

[4] A.J. Barker, J.G. Kettle, A.W. Faull, Indole Derivatives and Their Use as MCP-1 Antagonist, Zeneca Ltd., UK, WO/99/40914, 1999. 
[5] A.M. Birch, A.D. Morley, A. Stocker, P.R.O. Whittamore, Heterocyclic Amide Derivatives as Inhibitors of Glycogen Phosphorylase, Astrazeneca AB, WO/2003/ 074532, 2003.

[6] J.C. Arnould, Thieno-pyrrole Compounds as Antagonists of Gonadotropin Releasing Hormone, Astrazeneca AB, WO/2004/018479, 2004.

[7] J.B. Blair, D. Marona-Lewicka, A. Kanthasamy, V.L. Lucaites, D.L. Nelson, D.E. Nichols, Thieno[3,2- $b]$ - and thieno[2,3-b]pyrrole bioisosteric analogues of the hallucinogen and serotonin agonist $\mathrm{N}, \mathrm{N}$-dimethyltryptamine, J. Med. Chem. 42 (1999) 1106-1111.

[8] Y.-Q. Fang, J. Yuen, M. Lautens, A general modular method of azaindole and thienopyrrole synthesis via Pd-catalyzed tandem couplings of gemdichloroolefins, J. Org. Chem. 72 (2007), 5152-5160 (and references cited therein).

[9] K.E. Chippendale, B. Iddon, H. Suschitzky, Condensed thiophene ring systems. Part X. Synthesis and reactions of 2-aryl-1H-[1]benzothieno[2,3-b]pyrroles and 2-aryl-1H-[1]benzothieno[3,2-b]pyrroles, J. Chem. Soc. Perkin I (1973) 125-129.

[10] A.S. Abreu, N.O. Silva, P.M.T. Ferreira, M.-J.R.P. Queiroz, M. Venanzi, New $\beta, \beta-$ Bis(benzo $[b]$ thienyl)dehydroalanine derivatives: synthesis and cyclization, Eur. J. Org. Chem. (2003) 4792-4796.

[11] R. Banerjee, Liposomes: applications in medicine, J. Biomater. Appl. 16 (2001) 3-21.

[12] B.R. Lentz, Membrane "fluidity" as detected by diphenylhexatriene probes, Chem. Phys. Lipids 50 (1989) 171-190.

[13] J.N. Demas, G.A. Crosby, The measurement of photoluminescence quantum yields. A review, J. Phys. Chem. 75 (1971) 991-1024.

[14] S. Fery-Forgues, D. Lavabre, Are fluorescence quantum yields so tricky to measure? A demonstration using familiar stationery products, J. Chem. Educ. 76 (1999) 1260-1264

[15] J.V. Morris, M.A. Mahaney, J.R. Huber, Fluorescence quantum yield determinations. 9,10-Diphenylanthracene as a reference standard in different solvents, J. Phys. Chem. 80 (1976) 969-974.

[16] J.R. Lakowicz, Principles of Fluorescence Spectroscopy, 2nd edition, Kluwer Academic/Plenum Press, New York, 1999.

[17] N. Mataga, T. Kubota, Molecular Interactions and Electronic Spectra, Marce Dekker, New York, 1970.

[18] P. Skehan, R. Storeng, D. Scudiero, A. Monks, J. McMahon, D. Vistica, J.T. Warren, H. Bokesch, S. Kenny, M.R. Boyd, New colorimetric cytotoxicity assay for anticancer-drug screening, J. Natl. Cancer Inst. 82 (1990) 1107-1112.

[19] A. Monks, D. Scudiero, P. Skehan, R. Shoemaker, K. Paul, D. Vistica, C. Hose, J Langley, P. Cronise, A. Vaigro-Wolff, M. Gray-Goodrich, H. Campbell, J. Mayo, M. Boyd, Feasibility of a high-flux anticancer drug screen using a diverse panel of cultured human tumor cell lines, J. Natl. Cancer Inst. 83 (1991) 757-766.

[20] M.-J.R.P. Queiroz, A.S. Abreu, M.S.D. Carvalho, P.M.T. Ferreira, N. Nazareth, M.S.J. Nascimento, Synthesis of new heteroaryl and heteroannulated indoles from dehydrophenylalanines: antitumor evaluation, Bioorg. Med. Chem. 16 (2008) 5584-5589.

[21] M.-J.R.P. Queiroz, R.C. Calhelha, L.A. Vale-Silva, E. Pinto, M.S.-J. Nascimento, Synthesis of novel 3-(aryl)benzothieno[2,3-c]pyran-1-ones from Sonogashira products and intramolecular cyclization: antitumoral activity evaluation, Eur. J. Med. Chem. 44 (2009) 1893-1899.

[22] C.A. Frederick, L.D. Williams, G. Ughetto, G.A. van der Marel, J.H. van Boom, A. Rich, A.H. Wang, Structural comparison of anticancer drug-DNA complexes: adriamycin and daunomycin, Biochemistry 29 (1990) 2538-2549.
[23] B. Valeur, Molecular Fluorescence-Principles and Applications, Wiley-VCH, Weinheim, 2002.

[24] N.J.Turro, Modern Molecular Photochemistry, Benjamin/Cummings Pub, Menlo Park, CA, 1978.

[25] M.-J.R.P. Queiroz, E.M.S. Castanheira, A.M.R. Pinto, I.C.F.R. Ferreira, A. Begouin, $G$. Kirsch, Synthesis of the first thieno- $\delta$-carboline. Fluorescence studies in solution and in lipid vesicles, J. Photochem. Photobiol. A: Chem. 181 (2006) 290-296.

[26] M.-J.R.P. Queiroz, E.M.S. Castanheira, T.C.T. Lopes, Y.K. Cruz, G. Kirsch, Synthesis of fluorescent tetracyclic lactams by a "one pot" three steps palladiumcatalyzed borylation, Suzuki coupling (BSC) and lactamization. DNA and polynucleotides binding studies, J. Photochem. Photobiol. A: Chem. 190 (2007) $45-52$.

[27] D.R. Lide (Ed.), Handbook of Chemistry and Physics, 83rd edition, CRC Press, Boca Raton, 2002.

[28] (a) K.C. James, P.R. Noyce, Hydrogen bonding between testosterone propionate and solvent in chloroform-cyclohexane solutions, Spectrochim. Acta A 27 (1971) 691-696;

(b) G.R. Wileylb, S.I. Miller, Thermodynamic parameters for hydrogen bonding of chloroform with Lewis Bases in cyclohexane. A proton magnetic resonance study, J. Am. Chem. Soc. 94 (1972) 3287-3293.

[29] M.W. Schmidt, K.K. Baldridge, J.A. Boatz, S.T. Elbert, M.S. Gordon, J.H. Jensen, S. Koseki, N. Matsunaga, K.A. Nguyen, S. Su, T.L. Windus, M. Dupuis, J.A. Montgomery, General atomic and molecular electronic structure system, J. Comput. Chem. 14 (1993) 1347-1363.

[30] F. Jensen, Introduction to Computational Chemistry, John Wiley \& Sons, West Sussex, England, 1999.

[31] Z.R. Grabowski, K. Rotkiewicz, W. Rettig, Structural changes accompanying intramolecular electron transfer; focus on TICT states and structures, Chem. Rev. 103 (2003) 3899-4031.

[32] M.-J.R.P. Queiroz, E.M.S. Castanheira, M.S.D. Carvalho, A.S. Abreu, P.M.T Ferreira, H. Karadeniz, A. Erdem, New tetracyclic heteroaromatic compounds based on dehydroamino acids. Photophysical and electrochemical studies of interaction with DNA, Tetrahedron 64 (2008) trochemical

[33] J.R. Silvius, Thermotropic phase transitions of pure lipids in model membranes and their modifications by membrane proteins, in: Lipid-Protein Interactions, John Wiley \& Sons, New York, 1982.

[34] G.E.S. Toombes, A.C. Finnefrock, M.W. Tate, S.M. Gruner, Determination of $\mathrm{L}_{\alpha}-\mathrm{H}_{\text {II }}$ phase transition temperature for 1,2-dioleoyl-sn-glycero-3phosphatidylethanolamine, Biophys. J. 82 (2002) 2504-2510.

[35] D. Papahadjopoulos, N. Miller, Phospholipid model membranes. I. Structura characteristics of hydrated liquid crystals, Biochim. Biophys. Acta 135 (1967) 624-638.

[36] S.J. Strickler, R.A. Berg, Relationship between absorption intensity and fluorescence lifetime of molecules, J. Chem. Phys. 37 (1962) 814

[37] E.M.S. Castanheira, A.S. Abreu, M.S.D. Carvalho, M.-J.R.P. Queiroz, P.M.T. Ferreira, Fluorescence studies on potential antitumoral heteroaryl and heteroannulated indoles in solution and in lipid membranes, J. Fluorescence 19 (2009) 501-509.

[38] J.M. Seddon, Structure of the inverted hexagonal $\left(\mathrm{H}_{\text {II }}\right)$ phase and non-lamellar phase transitions in lipids, Biochim. Biophys. Acta 1031 (1990) 1-69. 